\title{
Rituximab in ANCA-Associated Vasculitis: Fad or Fact?
}

\author{
Fernando C. Fervenza \\ Division of Nephrology and Hypertension, Mayo Clinic College of Medicine, Rochester, Minn., USA
}

\section{Key Words}

Rituximab · High-dose glucocorticosteroids .

Cyclophosphamide

\begin{abstract}
A number of case reports and case series of patients with Wegener's granulomatosis, microscopic polyangiitis and Churg-Strauss syndrome have supported the use of rituximab (RTX) for the treatment of refractory ANCA-associated vasculitis (AAV). Whether B cell depletion with RTX could replace cyclophosphamide as a first-line therapy for patients with severe AAV remains to be proven. Two studies, recently published in the New England Journal of Medicine, have examined the efficacy of RTX in inducing remission in patients with severe AAV.

Copyright $\odot 2010$ S. Karger AG, Basel
\end{abstract}

Antineutrophil cytoplasmic antibody (ANCA)-associated vasculitis (AAV) comprises 3 heterogeneous syndromes: Wegener's granulomatosis (WG), microscopic polyangiitis (MPA) and the Churg-Strauss syndrome [1]. These 3 multisystem disorders are characterized by necrotizing small vessel vasculitis with a predilection for the kidneys, lungs and peripheral nervous system that share the occurrence of ANCA in most patients at the time of initial presentation [2-5].

Untreated, systemic AAV follows a progressive course with a fatal outcome due to vital organ failure. The combination of high-dose glucocorticosteroids (GCS) and cy-

\section{KARGER}

Fax +41613061234 E-Mail karger@karger.ch www.karger.com

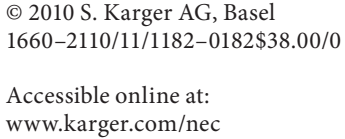

clophosphamide (CYC) has substantially improved the prognosis of these patients, turning a universally fatal illness into a chronically relapsing disease process [6-8]. However, not all patients respond to CYC, and up to $50 \%$ of the patients who respond to initial therapy relapse within the first 3-5 years [9]. In addition, CYC is associated with serious acute and long-term adverse effects, e.g. bone marrow suppression, infection, infertility, secondary malignancies and hemorrhagic cystitis, that result in treatment-related morbidity and mortality rivaling that caused by the underlying disease $[6,7]$. Therefore, effective therapies that could avoid the CYC-related toxicity have long been sought.

There is considerable evidence for a critical role of B lymphocytes in the regulation of immune responses, the production of antibodies and the pathogenesis of a number of autoimmune diseases [10]. B lymphocytes are also responsible for the production of autoantibodies, including ANCA, which have been implicated in the pathogenesis of several forms of vasculitis [11-13]. Further support for targeting B cells comes from observations that activated peripheral $\mathrm{B}$ cells are associated with disease activity and severity $[14,15]$. The most effective agent currently available for the treatment of AAV, namely CYC, has profound effects on B cells including inhibition of cell activation and proliferation, as well as suppression of immunoglobulin production $[8,16]$.

The rationale that $B$ cells are involved in the pathogenesis of AAV led us to treat a 66-year-old male with WG who was failing standard therapy with GCS + CYC, with GCS + rituximab (RTX), a chimeric monoclonal anti- 
body directed against CD20+B cells [17]. Treatment with 4 weekly doses of RTX at $375 \mathrm{mg} / \mathrm{m}^{2}$ led to clinical remission 2 months after the start of therapy. This initial success prompted the use of the same RTX regimen in an additional 10 patients with PR3-ANCA-positive WG who were resistant or had contraindications to the use of CYC [18]. Clinical remission, commensurate with a significant decrease in ANCA levels, was induced in all patients, and all patients were able to discontinue GCS over the course of 5 months. Adverse effects were minimal and generally related to the first infusion. These encouraging results were confirmed by a subsequent prospective open-label pilot trial in 10 patients with active and refractory ANCA-positive WG or MPA treated with the same RTX dosing regimen and a strictly protocolized oral GCS tapering [19]. Again, remission was induced in all patients. Although 1 patient relapsed once peripheral blood B lymphocytes had recovered, when retreated with the same regimen he achieved complete remission. These results suggest that either B lymphocytes or short-lived plasma cells (or both) rather than long-lived plasma cells are the cellular source of ANCA [17-19].

In these studies, ANCA titers declined in all of the patients and became negative in most following RTX therapy. Long-lived plasma cells are not affected by anti-CD20 therapy. Consequently, as in other autoimmune diseases [20], B lymphocytes and short-lived plasma cells (which are dependent on antigen-specific B lymphocyte progenitors) seem to be primarily responsible for autoantibody production. Furthermore, ANCA level increases coincided or followed B lymphocyte reconstitution [19]. These findings suggest that, like in rheumatoid arthritis [21, 22], autoantibody production is dependent on B lymphocytes. This is in contrast to total immunoglobulin $\mathrm{G}$ and protective antibodies, which are produced by long-lived plasma cells and unaffected by RTX therapy [21]. However, it is possible that in different diseases, autoantibodies may be produced by different types of plasma cells, e.g. SLE, since treatment with RTX has no effect on anti-double-stranded DNA antibody levels in these patients [23].

Following our initial observations, a number of case reports and case series of patients with WG, MPA and Churg-Strauss syndrome have supported the use of RTX for the treatment of refractory AAV [24-33], as well as for maintenance therapy in patients with AAV [34]. A number of subsequent reports, however, have cast doubt on the efficacy of RTX in refractory WG $[35,36]$. Failure to therapy was attributed to patients having a granulomatous as opposed to a vasculitic form of the disease, implying that RTX is ineffective in patients in whom granulo- matous manifestations predominated. In our experience, however, both vasculitic and granulomatous forms of AAV respond to RTX, indicating that factors other than differences in disease manifestations explain the observed discrepancy in outcome, e.g. differences in RTX dosing $[18,19]$. Until recently, that was all the evidence supporting the use of B-cell target therapy in patients with severe AAV. Whether B cell depletion with RTX could replace CYC as a first-line therapy for patients with severe AAV remained to be proven.

Two studies published in the New England Journal of Medicine examined the efficacy of RTX in inducing remission in patients with severe AAV $[37,38]$. The cardinal differences between the studies are outlined in table 1 . In the first study, 'Rituximab versus Cyclophosphamide in ANCA-Associated Renal Vasculitis' (RITUXVAS), Jones et al. [37], randomized 44 patients with newly diagnosed AAV and renal involvement to receive standard GCS regimen plus either RTX $\left(375 \mathrm{mg} / \mathrm{m}^{2}\right.$ i.v. weekly $\left.\times 4\right)$ with 2 intravenous CYC pulses given concomitantly with the 1 st and 3rd RTX infusion (33 patients, the RTX group), or intravenous CYC for 3-6 months followed by azathioprine (11 patients, the control group) [37]. The rate of sustained remission [defined as BVAS (Birmingham Vasculitis Activity Score) of 0 for $\geq 6$ months] at 12 months was similar in both treatment arms. GFR improved equally in both groups. Similarly, the percentage of severe adverse events, another of the primary endpoints of the study, was not different between the groups (RTX $42 \%$; control 36\%), and although 6 deaths occurred among patients treated with the combination of RTX and CYC, the percentage of deaths was the same in both treatment groups (18\%).

In the same issue of the journal, the results of a much larger study were also reported in 'Rituximab versus Cyclophosphamide for ANCA-Associated Vasculitis' (RAVE), a report on a multicenter randomized, doubleblind, double placebo-controlled trial conducted to evaluate the efficacy and safety of RTX for remission induction in severe AAV in comparison to CYC [38]. A total of 197 patients with severe WG or MPA (3:1), all positive for PR3-ANCA or MPO-ANCA (2:1), were randomized to receive treatment with RTX $\left(375 \mathrm{mg} / \mathrm{m}^{2}\right.$ i.v. weekly $\left.\times 4\right)$ or CYC $(2 \mathrm{mg} / \mathrm{kg} / \mathrm{d}$ p.o.) in combination with GCS. Initial GCS treatment was the same in both groups (1-3 g i.v. methylprednisolone) and was followed by rigorously protocolized GCS tapering, aimed at complete discontinuation of GCS by month 5 . Once remission was achieved, patients on CYC were switched to maintenance therapy with azathioprine, while patients on RTX were switched to placebo. Equally distributed among the groups were 
Table 1. Main characteristics of the trials

\begin{tabular}{|c|c|c|c|}
\hline & \multicolumn{2}{|l|}{ RITUXIVAS } & RAVE \\
\hline Methods & \multicolumn{2}{|c|}{$\begin{array}{l}\text { randomized 3:1; open-label, 2-group, parallel-designed } \\
\text { trial }\end{array}$} & $\begin{array}{l}\text { randomized } 1: 1 \text {, double-blind, double-dummy, } \\
\text { noninferiority trial }\end{array}$ \\
\hline Number of patients & \multicolumn{2}{|l|}{44} & 197; follow-up at 6 months completed in 165 \\
\hline Inclusion criteria & \multicolumn{2}{|l|}{ newly diagnosed AAV with renal involvement } & newly diagnosed (49\%) or severe relapsing AAV (51\%) \\
\hline Patient characteristics & \multicolumn{2}{|l|}{$\begin{array}{l}\mathrm{WG}=22 \\
\mathrm{MPA}=16 \\
\text { renal-limited vasculitis }=6\end{array}$} & $\begin{array}{l}\mathrm{WG}=148 \\
\mathrm{MPA}=48 \\
\text { undetermined }=1\end{array}$ \\
\hline BVAS $^{\mathrm{a}}$ & \multicolumn{2}{|l|}{$\mathrm{RTX}=19(14-24)$ vs. $\mathrm{CYC}=18(12-25)^{\mathrm{c}}$} & $\mathrm{RTX}=8.5 \pm 3.2$ vs. $\mathrm{CYC}=8.2 \pm 3.2^{\mathrm{d}}$ \\
\hline Estimated GFR ${ }^{\mathrm{b}}$ & \multicolumn{2}{|l|}{$\mathrm{RTX}=20(5-44)$ vs. $\mathrm{CYC}=12(9-33)^{\mathrm{c}}$} & $\mathrm{RTX}=53.8 \pm 29.8 ;$ CYC $68.9 \pm 41.6^{\mathrm{d}}$ \\
\hline ANCA by immunofluorescence & \multicolumn{2}{|l|}{$\begin{array}{l}\text { RTX }=20 \text { C-ANCA } ; 13 \text { P-ANCA } \\
\text { CYC }=5 \text { C-ANCA } ; 6 \text { P-ANCA }\end{array}$} & $\begin{array}{l}\text { RTX }=66 \text { C-ANCA; } 33 \text { P-ANCA } \\
\text { CYC }=62 \text { C-ANCA; } 34 \text { P-ANCA }\end{array}$ \\
\hline Induction therapy & \multicolumn{2}{|l|}{$\mathrm{RTX}+\mathrm{CYC}^{\mathrm{e}}+\mathrm{GCS}$ vs. $\mathrm{CYC}^{\mathrm{f}}+\mathrm{GCS}$} & $\mathrm{RTX}+\mathrm{GCS}$ vs. $\mathrm{CYC}^{\mathrm{g}}+\mathrm{GCS}$ \\
\hline Methylprednisolone, g & \multicolumn{2}{|l|}{$1-2^{\mathrm{h}}$} & $1-3^{\mathrm{i}}$ \\
\hline Target GCS dose & \multicolumn{2}{|l|}{$5 \mathrm{mg}$ at 6 months } & 0 at 6 months \\
\hline Maintenance therapy & \multicolumn{2}{|l|}{$\begin{array}{l}\text { RTX group }=; \text { low-dose GCS } \\
\text { CYC group }=\text { AZA }^{j}+\text { low-dose GCS }\end{array}$} & $\begin{array}{l}\text { RTX group - placebo } \\
\text { CYC group - AZA }\end{array}$ \\
\hline Antibiotic prophylaxis & \multicolumn{2}{|l|}{ recommended } & mandatory \\
\hline Primary endpoints & \multicolumn{2}{|c|}{$\begin{array}{l}\text { sustained remission rates at } 12 \text { months and serious } \\
\text { adverse events }\end{array}$} & $\begin{array}{l}\text { complete remission and successful prednisone taper by } 6 \\
\text { months }\end{array}$ \\
\hline Severe adverse events & \multicolumn{2}{|l|}{ similar in both groups (RTX 42\%; control 36\%) } & more selected adverse events ${ }^{\mathrm{k}}$ in the CYC group \\
\hline Outcomes & \multicolumn{2}{|c|}{$\begin{array}{l}\text { RTX-based therapy not superior to CYC-based treatment. } \\
\text { Sustained remissions achieved in (25/33) 76\% of RTX- } \\
\text { based group and }(9 / 11) 82 \% \text { of the CYC-based group } \\
(\mathrm{p}=0.68)\end{array}$} & $\begin{array}{l}\text { RTX-based therapy not inferior to daily CYC treatment for } \\
\text { induction of remission. Primary end point achieved in } \\
(63 / 99) 64 \% \text { in RTX group and }(52 / 98) 53 \% \text { in CYC group } \\
(\mathrm{p}<0.001)\end{array}$ \\
\hline Efficacy in relapsing disease & \multicolumn{2}{|l|}{ not tested } & RTX superior to CYC \\
\hline Severe flares & \multicolumn{2}{|l|}{ not reported } & $\mathrm{RTX}=6 ; \mathrm{CYC}=10$ \\
\hline \multicolumn{2}{|c|}{$\begin{array}{l}\text { RTX = Rituximab-treated group; CYC }=\text { cyclophosphamide-treated } \\
\text { group; AZA = azathioprine. } \\
\text { a RITUXVAS used BVAS, whereas RAVE used BVAS/WG. BVAS scores } \\
\text { are about twice what BVAS/WG scores are [34]. } \\
{ }^{b} \text { eGFR for RAVE is based on results from patients with } \geq 1 \text { severe renal } \\
\text { item scored on BVAS/WG }(\mathrm{n}=99 ; \mathrm{RTX}=49, \mathrm{CYC}=50 \text { ). } \\
{ }^{\mathrm{c}} \text { Median and interquartile range. } \\
{ }^{\mathrm{d}} \text { Mean } \pm \text { SD. } \\
{ }^{\mathrm{e}} \text { CYC given i.v. at a dose of } 15 \mathrm{mg} / \mathrm{kg} \text { with the } 1 \text { st and } 3 \mathrm{rd} \text { RTX infusion; } \\
\text { a } 3 \text { rd dose was allowed for patients with progressive disease. } \\
{ }^{\mathrm{f}} \text { CYC given i.v. at a dose of } 15 \mathrm{mg} / \mathrm{kg} \text { every } 2 \text { weeks for the first } 3 \text { doses, } \\
\text { then every } 3 \text { weeks (minimum } 6, \text { maximum } 10 \text { doses). }\end{array}$} & $\begin{array}{l}{ }^{\mathrm{g}} \mathrm{CYC} \text { gi } \\
\text { h Patients } \\
\text { well as plasm } \\
{ }^{\mathrm{i}} \text { Patients } \\
\text { therapy. } \\
{ }^{\mathrm{j}} \text { AZA giv } \\
{ }^{\mathrm{k}} \text { Selected } \\
2 \text { or higher le } \\
\text { venous thron } \\
\text { tions that cor }\end{array}$ & $\begin{array}{l}\text { orally at a dose of } 2 \mathrm{mg} / \mathrm{kg} / \mathrm{day} \text {. } \\
\text { were allowed to receive i.v. methylprednisolone (up to } 2 \mathrm{~g} \text { ) as } \\
\text { exchange before enrolment. } \\
\text { received } 1-3 \mathrm{~g} \text { i.v. methylprednisolone as part of induction } \\
\text { n at a dose of } 2 \mathrm{mg} / \mathrm{kg} / \mathrm{day} \text {. } \\
\text { adverse events were prespecified as death, malignancy, grade } \\
\text { kopenia, grade } 3 \text { or higher infections, drug-induced cystitis, } \\
\text { boembolic events, stroke, hospitalization and infusion reac- } \\
\text { raindicate further infusions. }\end{array}$ \\
\hline
\end{tabular}

the disease severity, organ involvement, AAV type and ANCA type.

The study also included an equal number of patients with newly diagnosed and relapsing disease. Sixty-three (64\%) of the patients in the RTX arm versus 52 (53\%) in the CYC arm achieved the primary endpoint of the study defined as disease remission with a BVAS/WG of 0 in the absence of GCS therapy at month 6 , a result that met the criterion for noninferiority $(\mathrm{p}<0.001)$. There was no difference in treatment response within the subgroups of patients with major renal involvement $(n=99)$ or alveolar hemorrhage $(n=50)$. It should be noted that RITUXVAS used BVAS, whereas RAVE used BVAS/WG. BVAS scores are approximately twice the values of BVAS/WG [39]. A 
larger proportion of patients in the RTX group achieved the primary endpoint than in the CYC group, with results falling short of achieving superiority for the RTX group $(p=0.09)$. Similarly, $71 \%$ of the patients in the RTX group versus $62 \%$ of the patients in the CYC group reached the secondary outcome of disease remission while receiving a daily prednisone dose $<10 \mathrm{mg}$. This suggests that aiming to discontinue GCS treatment in all patients at 6 months may result in lower remission rates and may not be achievable in all patients.

There was no difference between RTX and CYC for treatment-naive patients. In addition, some of the relapsing patients were $\mathrm{CYC}$ naive, too (they developed a severe flare after having previously been treated for limited disease with MTX). Furthermore, the WGET trial has clearly shown that relapsing patients respond exactly the same as new disease patients to repeat remission induction with CYC [40]. However, it is important to observe that RTX was more efficient than CYC in inducing remission in patients with relapsing disease.

One major disadvantage of CYC in a relapsing disease is that its toxicities are cumulative. Decades of experience with CYC have confirmed that the incremental toxicity is substantial. This in itself is a major benefit for the use of RTX because it is in this patient population that problems with cumulative CYC exposure are likely to occur. The results of RAVE are not likely to be explained by the use of high-dose GCS as RAVE did not use more GCS than any of the other clinical trials published in the literature, and the quantities of methylprednisolone used in RAVE were similar between the 2 groups. Although not statistically different, the mean cumulative dose of prednisone used in the first 6 months was in fact lower in the RTX group $(3,595 \pm 999 \mathrm{mg})$ than in the CYC group $(3,977 \pm$ $1,183)$. If anything, the lower doses and shorter time on GCS used in RAVE could account for the somewhat lower remission rates observed when compared with studies that use GCS at higher doses and for longer periods of time $[41,42]$.

The number of total adverse events, serious adverse events, or nondisease-related adverse events were similar between the RTX and CYC groups, but fewer patients in the RTX group experienced 1 or more of the protocoldefined selected adverse events ( 22 vs. 32 patients; $\mathrm{p}=$ 0.01 ). The 9 selected adverse events (death, malignancy, grade 2 or higher leukopenia, grade 3 or higher infections, drug-induced cystitis, venous thromboembolic events, stroke, hospitalization and infusion reactions that preclude further infusions) were agreed upon in advance with the FDA. The difference between the 2 groups re- lated principally to the higher likelihood of leukopenia among patients treated with CYC.

As discussed above, similar results for adverse events were reported in the RITUXVAS trial. For several reasons, this is not surprising: First, the reporting of adverse events includes not only those events believed to be related directly to either CYC or RTX, but also to GCS. Second, events related to disease activity are also reported as adverse events and can continue to occur for some weeks after the initiation of therapy. Third, some of the important adverse events associated with CYC are not anticipated to occur until after the completion of the trial. This pertains particularly to the effects of CYC upon infertility, bone marrow function and cancer incidence.

A total of 7 patients developed cancer at some point during the course of RAVE. Two patients ( 1 in each treatment arm) had prostate cancer diagnosed within the first 6 months of the study. Subsequently, an additional 6 cancers developed: 5 in the RTX group ( 2 in the same patient) and 1 in the CYC group. No particular pattern to the types of malignancies was observed. As pointed out by the authors, the data is confounded by the fact that more than half of the patients had been treated with multiple immunosuppressive agents known to be associated with an increased risk of cancer before enrollment in the trial. Only 2 patients developed cancer in the RITUXVAS trial, both of which received RTX. The extended follow-up data of RAVE will also provide information about the longterm risk of malignancy of RTX versus CYC.

RTX has generated attention for its potential role in the development of unusual infections, such as progressive multifocal leukoencephalopathy (PML), following the report of 2 cases of fatal PML in patients treated with RTX for systemic lupus erythematosus (SLE) [43-45]. Although the risk for PML following RTX is real, it should be remembered that over half a dozen cases of PML have been reported in patients with AAV who never received RTX [46-52]. Similarly, there have been over 20 cases of PML in patients with SLE who never received RTX [53]. In patients with SLE, the intensity of immunosuppression in the months preceding the development of the neurologic symptoms was highly variable. While 5 of the 20 SLE patients in whom this information was available had received alkylating agents, 8 had been treated with only low-dose prednisone (15 mg/day) and/or an antimalarial agent, and 1 patient had not received any recent immunosuppression treatment. PML has also been described in patients treated with mycophenolic acid $[54,55]$ and monoclonal antibodies that target the cell adhesion molecules VLA-4 (natalizumab; for multiple sclerosis and 
Crohn's disease) or LFA-1 (efalizumab; for severe forms of plaque psoriasis; no longer on the market) $[56,57]$. These observations suggest that PML is not caused by a particular agent, but rather by factors other than immunosuppression therapy in patients with rheumatic diseases, particularly in those with SLE [53].

A salient question that remains to be answered is the durability of the remission induced by RTX. In RITUXVAS, $15 \%$ of the patients in the RTX group and $10 \%$ in the CYC group had a relapse during the 12-month follow-up period. In RAVE, flare rates at 6 months were similar between the groups, but the 18-month follow-up data is not yet available. It should be noted that the CYC group in both trials received maintenance immunosuppression with azathioprine ( \pm low-dose GCS), whereas the RTX group in RITUXVAS were placed on low-dose GCS, and on placebo in RAVE. The ability to achieve long-term remission without the requirement of maintenance therapy can be considered an advantage of RTX regarding quality of life, but should not be interpreted as a sign that patients are no longer immunosuppressed. Our experience with RTX in patients with AAV suggests that long-term remission can be achieved with RTX monotherapy and preliminary analysis of the 18-month follow-up in RAVE shows that 1 single course of RTX is sufficient to keep patients in remission long-term without increasing the number of side effects or the relapse rate compared to patients maintained on AZA. Thus, do not be mistaken: patients who are B-cell depleted are immunosuppressed - they just do not need to take the pills!

It is interesting that all patients treated with the combination of RTX and CYC in the RITUXVAS trial became ANCA negative while only half of the patients in RAVE had similar results. Although ANCA-negativity is not a necessary condition to achieve remission, it is highly associated with the maintenance of remission $[58,59]$. Does this mean that regimens that used RTX in combination with CYC would be more effective than RTX used without CYC? But will this result in a more toxic regimen? In fact, the $18 \%$ mortality rate observed in RITUXVAS (versus $1.5 \%$ in RAVE) may have resulted from over immunosuppression caused by the combined used of RTX and CYC in a group of patients that were older and had more severe renal disease than patients enrolled in RAVE. Our experience at the Mayo Clinic and the results of RAVE trial show that RTX does not need to be combined with CYC.

There is also a question regarding the correct dosing of RTX in patients with AAV. Both RITUXVAS and RAVE used $375 \mathrm{mg} / \mathrm{m}^{2}$ of body-surface area per week for 4 weeks. In patients with membranous nephropathy, RTX given as $1 \mathrm{~g} \times 2$ is equally effective as RTX given as 375 $\mathrm{mg} / \mathrm{m}^{2} \times 4$ [60]. Whether the more convenient 2-dose regimen currently used for rheumatoid arthritis has similar efficacy in AAV remains to be tested.

Further studies are also needed to determine the efficacy of RTX in patients who are ANCA-negative or in those with limited WG. Similarly, patients with severe alveolar hemorrhage or with serum creatinine $>4 \mathrm{mg} / \mathrm{dl}$ at the time of screening were excluded from RAVE for ethical reasons. On the other hand, the RITUXVAS trial included 9 patients that were dialysis-dependent, with 6 of the 8 patients in the RTX group achieving sustained remission, and 5 actually came off dialysis. Thus, RTX appears to be effective in the group of patients whose renal disease severity recommends using plasma exchange, but further research is needed.

There are also questions regarding the long-term efficacy or safety of RTX. We recently reviewed our 10-year experience in 108 patients who received at least 1 course of RTX for remission induction or remission maintenance in AAV (patients enrolled in RAVE were excluded) [61]. All achieved remission as measured by a BVAS/ $\mathrm{WG}=0$. Fifty-three patients (median age: 46, IQR: 28-61; $53 \%$ women) received subsequent courses of RTX for relapses or to maintain remission. All but 1 patient were PR3/ANCA-positive. These 53 patients received a median of 4 courses (IQR 3-5) of RTX (200 courses of 4-weekly infusions at $375 \mathrm{mg} / \mathrm{m}^{2}$, and 10 courses of biweekly infusions of 1,000 mg). All observed relapses occurred after reconstitution of $\mathrm{B}$ cells and were accompanied or preceded by an increase in ANCA levels except in 1 patient. A total of 72 (34\%) courses of RTX were given due to relapse (achieving remission in all individuals) and 138 (66\%) courses were given preemptively due to either B cell reconstitution or following the increase of both $B$ cells and ANCA levels. During the period of B cell depletion, 8 infectious complications were observed (5 upper respiratory tract infections, 2 pneumonias and 1 skin infection; only 1 patient with pneumonia required hospitalization). All further evidence that RTX is effective and safe for induction and maintenance of remission in patients with relapsing AAV and that prolonged B cell depletion seems to be associated with a low risk of infections.

RAVE and RITUXVAS have paved the way to find new and better therapies for patients with AAV. They leave us now poised to find answers for the remaining questions. RAVE and RITUXVAS are the first trials to challenge the dogma stated almost 30 years ago that 'given our earlier results on the induction of complete remissions in patients with Wegener's granulomatosis with the cyclo- 
phosphamide and prednisone regimen, and the fact that clearly corticosteroids alone are ineffective in inducing remissions in Wegener's granulomatosis, we felt that a truly randomized trial - in which patients with a uniformly fatal disease would be assigned to a treatment group using a regimen that we know cures the disease or to another using a regimen in which the outcome is uncertain - would be unethical' [62].
The results of RITUXVAS and RAVE demonstrate, unequivocally, that RTX combined with GCS or with GCS and CYC is not inferior to the standard therapy for the induction of remissions in patients with severe AAV, and is better than CYC for patients with relapsing disease. This places RTX-based therapies as a legitimate alternative to CYC in the treatment of AAV. Thus, coming back to the initial question of whether RTX is a fad or a fact? I have no hesitation in saying that RTX in AAV is, in my mind, a fact!

\section{References}

1 Jennette JC, Falk RJ, Andrassy K, et al: Nomenclature of systemic vasculitides. Proposal of an international consensus conference. Arthritis Rheum 1994;37:187-192.

-2 Finkielman JD, Lee AS, Hummel AM, et al: ANCA are detectable in nearly all patients with active severe Wegener's granulomatosis. Am J Med 2007;120:643.e9-e14.

$\checkmark 3$ Guillevin L, Cohen P, Gayraud M, et al: Churg-Strauss syndrome. Clinical study and long-term follow-up of 96 patients. Medicine (Baltimore) 1999;78:26-37.

-4 Guillevin L, Durand-Gasselin B, Cevallos R, et al: Microscopic polyangiitis: clinical and laboratory findings in eighty-five patients. Arthritis Rheum 1999;42:421-430.

$\checkmark 5$ Keogh KA, Specks U: Churg-Strauss syndrome: clinical presentation, antineutrophil cytoplasmic antibodies, and leukotriene receptor antagonists. Am J Med 2003;115:284290.

-6 Fauci AS: Vasculitis. J Allergy Clin Immunol 1983;72:211-223.

7 Hoffman GS, Kerr GS, Leavitt RY, et al: Wegener granulomatosis: an analysis of 158 patients. Ann Intern Med 1992;116:488-498.

$>8$ Fauci AS, Katz P, Haynes BF, Wolff SM: Cyclophosphamide therapy of severe systemic necrotizing vasculitis. N Engl J Med 1979; 301:235-238.

$\checkmark 9$ Nachman PH, Hogan SL, Jennette JC, Falk $\mathrm{RJ}$ : Treatment response and relapse in antineutrophil cytoplasmic autoantibody-associated microscopic polyangiitis and glomerulonephritis. J Am Soc Nephrol 1996;7: 33-39.

10 Dorner T, Jacobi AM, Lipsky PE: B cells in autoimmunity. Arthritis Res Ther 2009;11: 247.

-11 Huugen D, Tervaert JW, Heeringa P: Antineutrophil cytoplasmic autoantibodies and pathophysiology: new insights from animal models. Curr Opin Rheumatol 2004;16:4-8.

12 Jennette JC, Xiao H, Falk RJ: Pathogenesis of vascular inflammation by anti-neutrophil cytoplasmic antibodies. J Am Soc Nephrol 2006;17:1235-1242.

$\checkmark 13$ Clayton AR, Savage CO: Production of antineutrophil cytoplasm antibodies derived from circulating $B$ cells in patients with systemic vasculitis. Clin Exp Immunol 2003; 132:174-179.
14 Popa ER, Stegeman CA, Bos NA, et al: Differential B- and T-cell activation in Wegener's granulomatosis. J Allergy Clin Immunol 1999;103:885-894.

15 Stevenson HC, Fauci AS: Activation of human B lymphocytes. XII. Differential effects of in vitro cyclophosphamide on human lymphocyte subpopulations involved in Bcell activation. Immunology 1980;39:391397.

16 Cupps TR, Edgar LC, Fauci AS: Suppression of human B lymphocyte function by cyclophosphamide. J Immunol 1982;128:24532457.

17 Specks U, Fervenza FC, McDonald TJ, Hogan MC: Response of Wegener's granulomatosis to anti-CD20 chimeric monoclonal antibody therapy. Arthritis Rheum 2001;44: 2836-2840.

18 Keogh KA, Wylam ME, Stone JH, Specks U: Induction of remission by B lymphocyte depletion in eleven patients with refractory antineutrophil cytoplasmic antibody-associated vasculitis. Arthritis Rheum 2005;52: 262-268.

19 Keogh KA, Ytterberg SR, Fervenza FC, et al: Rituximab for refractory Wegener's granulomatosis: report of a prospective, open-label pilot trial. Am J Respir Crit Care Med 2006; 173:180-187.

20 Leyendeckers H, Tasanen K, Bruckner-Tuderman L, et al: Memory B cells specific for the NC16A domain of the $180 \mathrm{kDa}$ bullous pemphigoid autoantigen can be detected in peripheral blood of bullous pemphigoid patients and induced in vitro to synthesize autoantibodies. J Invest Dermatol 2003;120: 372-378.

21 Cambridge G, Leandro MJ, Edwards JC, et al: Serologic changes following B lymphocyte depletion therapy for rheumatoid arthritis. Arthritis Rheum 2003;48:2146-2154.

22 De Vita S, Zaja F, Sacco S, et al: Efficacy of selective B cell blockade in the treatment of rheumatoid arthritis: evidence for a pathogenetic role of B cells. Arthritis Rheum 2002; 46:2029-2033.

23 Looney RJ, Anolik JH, Campbell D, et al: B cell depletion as a novel treatment for systemic lupus erythematosus: a phase I/II dose-escalation trial of rituximab. Arthritis Rheum 2004;50:2580-2589.
24 Tamura N, Matsudaira R, Hirashima M, et al: Two cases of refractory Wegener's granulomatosis successfully treated with rituximab. Intern Med 2007;46:409-414.

25 Stasi R, Stipa E, Del Poeta G, et al: Long-term observation of patients with anti-neutrophil cytoplasmic antibody-associated vasculitis treated with rituximab. Rheumatology (Oxford) 2006;45:1432-1436.

26 Ferraro AJ, Day CJ, Drayson MT, Savage CO: Effective therapeutic use of rituximab in refractory Wegener's granulomatosis. Nephrol Dial Transplant 2005;20:622-625.

27 Eriksson P: Nine patients with anti-neutrophil cytoplasmic antibody-positive vasculitis successfully treated with rituximab. J Intern Med 2005;257:540-548.

28 Maher LV, Wilson JG: Successful treatment of rheumatoid vasculitis-associated foot drop with rituximab. Rheumatology $(\mathrm{Ox}-$ ford) 2006;45:1450-1451.

29 Koukoulaki M, Smith KG, Jayne DR: Rituximab in Churg-Strauss syndrome. Ann Rheum Dis 2006;65:557-559.

30 Pepper RJ, Fabre MA, Pavesio C, et al: Rituximab is effective in the treatment of refractory Churg-Strauss syndrome and is associated with diminished T-cell interleukin-5 production. Rheumatology (Oxford) 2008; 47:1104-1105.

31 Taylor SR, Salama AD, Joshi L, et al: Rituximab is effective in the treatment of refractory ophthalmic Wegener's granulomatosis. Arthritis Rheum 2009;60:1540-1547.

32 Smith KG, Jones RB, Burns SM, Jayne DR: Long-term comparison of rituximab treatment for refractory systemic lupus erythematosus and vasculitis: remission, relapse, and re-treatment. Arthritis Rheum 2006;54:2970-2982.

33 Jones RB, Ferraro AJ, Chaudhry AN, et al: A multicenter survey of rituximab therapy for refractory antineutrophil cytoplasmic antibody-associated vasculitis. Arthritis Rheum 2009;60:2156-2168.

34 Rhee EP, Laliberte KA, Niles JL: Rituximab as maintenance therapy for anti-neutrophil cytoplasmic antibody-associated vasculitis. Clin J Am Soc Nephrol 2010;5:1394-1400. 
35 Aries PM, Hellmich B, Voswinkel J, et al: Lack of efficacy of rituximab in Wegener's granulomatosis with refractory granulomatous manifestations. Ann Rheum Dis 2006; 65:853-858.

-36 Omdal R, Wildhagen K, Hansen T, et al: Anti-CD20 therapy of treatment-resistant Wegener's granulomatosis: favourable but temporary response. Scand J Rheumatol 2005; 34:229-232.

-37 Jones RB, Tervaert JW, Hauser T, et al: Rituximab versus cyclophosphamide in ANCAassociated renal vasculitis. $\mathrm{N}$ Engl J Med 2010;363:211-220.

38 Stone JH, Merkel PA, Spiera R, et al: Rituximab versus cyclophosphamide for ANCAassociated vasculitis. N Engl J Med 2010;363: 221-232.

>39 Merkel PA, Cuthbertson DD, Hellmich B, et al: Comparison of disease activity measures for anti-neutrophil cytoplasmic autoantibody (ANCA)-associated vasculitis. Ann Rheum Dis 2009;68:103-106.

40 Etanercept plus standard therapy for Wegener's granulomatosis. N Engl J Med 2005; 352:351-361.

41 Jayne D, Rasmussen N, Andrassy K, et al: A randomized trial of maintenance therapy for vasculitis associated with antineutrophil cytoplasmic autoantibodies. N Engl J Med 2003;349:36-44.

42 Pagnoux C, Mahr A, Hamidou MA, et al: Azathioprine or methotrexate maintenance for ANCA-associated vasculitis. N Engl J Med 2008;359:2790-2803.

43 Rituxan warning. FDA Consum 2007;41:3.

$\checkmark 44$ Harris HE: Progressive multifocal leucoencephalopathy in a patient with systemic lupus erythematosus treated with rituximab. Rheumatology (Oxford) 2008;47:224-225.
45 Ramos-Casals M, Soto MJ, Cuadrado MJ, Khamashta MA: Rituximab in systemic lupus erythematosus: a systematic review of off-label use in 188 cases. Lupus 2009; 18: 767-776.

46 Aksamit AJ: Treatment of non-AIDS progressive multifocal leukoencephalopathy with cytosine arabinoside. J Neurovirol 2001;7:386-390

$\checkmark 47$ Choy DS, Weiss A, Lin PT: Progressive multifocal leukoencephalopathy following treatment for Wegener's granulomatosis. JAMA 1992;268:600-601.

-48 Ettinger J, Feiden W, Hubner G, Schreiner M: Progressive multifocal leukoencephalopathy in Wegener's granulomatosis in relation to therapy with cyclosporin A (in German). Klin Wochenschr 1989;67:260-264.

49 Morgenstern LB, Pardo CA: Progressive multifocal leukoencephalopathy complicating treatment for Wegener's granulomatosis. J Rheumatol 1995;22:1593-1595.

50 Pagnoux C, Hayem G, Roux F, et al: JC virus leukoencephalopathy complicating Wegener's granulomatosis. Joint Bone Spine 2003; 70:376-379.

51 Terrier B, Martinez V, Seilhean D, et al: Progressive multifocal leukoencephalopathy mimicking cerebral vasculitis in systemic granulomatosis. J Infect 2007;54:e133-e135.

52 Wang HY: Pathologic quiz case: a 54-yearold deceased man with diffuse subcortical lesions of the central nervous system. Progressive multifocal leukoencephalopathy. Arch Pathol Lab Med 2004;128:e70-e72.

53 Calabrese LH, Molloy ES, Huang D, Ransohoff RM: Progressive multifocal leukoencephalopathy in rheumatic diseases: evolving clinical and pathologic patterns of disease. Arthritis Rheum 2007;56:21162128 .
54 Manfro RC, Vedolin L, Cantarelli M, et al: Progressive multifocal leukoencephalopathy in a kidney transplant recipient after conversion to mycophenolic acid therapy. Transpl Infect Dis 2009;11:189-190.

55 Neff RT, Hurst FP, Falta EM, et al: Progressive multifocal leukoencephalopathy and use of mycophenolate mofetil after kidney transplantation. Transplantation 2008;86: 1474-1478

56 Tan CS, Koralnik IJ: Progressive multifocal leukoencephalopathy and other disorders caused by JC virus: clinical features and pathogenesis. Lancet Neurol 2010;9:425-437.

57 Major EO: Progressive multifocal leukoencephalopathy in patients on immunomodulatory therapies. Annu Rev Med 2010;61:35-47.

58 Slot MC, Tervaert JW, Boomsma MM, Stegeman CA: Positive classic antineutrophil cytoplasmic antibody (C-ANCA) titer at switch to azathioprine therapy associated with relapse in proteinase 3-related vasculitis. Arthritis Rheum 2004;51:269-273.

59 Sanders JS, Huitma MG, Kallenberg CG, Stegeman CA: Prediction of relapses in PR3ANCA-associated vasculitis by assessing responses of ANCA titres to treatment. Rheumatology (Oxford) 2006;45:724-729.

60 Fervenza FC, Abraham RS, Erickson SB, et al: Rituximab therapy in idiopathic membranous nephropathy: a 2-year study. Clin J Am Soc Nephrol 2010, E-pub ahead of print.

61 Cartin-Ceba R, Golbin J, Keogh KA, et al: Rituximab for remission induction and maintenance in ANCA-associated vasculitis: a single-center ten-year experience in 108 patients. Arthritis \& Rheum 2010;62:S283.

62 Fauci AS, Haynes BF, Katz P: Assessing treatments with cyclophosphamide (in comment). Ann Intern Med 1983;98:1026-1027.

\section{Editorial Comment}

Meguid El Nahas, Sheffield

This review by Dr. Fervenza gives an update on the rapidly evolving field of vasculitis treatment. It reviews recent publications on the use of rituximab (a monoclonal anti-CD20 antibody) in ANCA-associated vasculitis (AAV). While the use of this relatively new therapy is effective and appealing, enthusiasm has to be tempered by a critical examination of the evidence which shows little advantage over conventional therapy with cyclophosphamide. Conclusions based on subgroup analyses need to be considered carefully as the power of such analyses precludes statistical evaluation. Finally, the risk:benefit consideration warrants longer follow-up. I find it intriguing that older less hazardous immunosuppressive treatments with agents such as azathioprine were never compared to cyclophosphamide in AAV, especially in older patients more susceptible to the toxicity of cyclophosphamide?! Original observations of superiority by Fauci and Wolf dating from the 1970s have seldom been read, but often quoted, in spite of the fact that they refer to maintenance therapy and frequency of relapses in those treated with azathioprine, not induction therapy. Such inferiority of azathioprine in maintenance therapy of AAV has been dismissed by the CYCAZAREM study. There has never been a randomized controlled trial of cyclophosphamide versus azathioprine for the induction of remission of AAV?! 